\title{
Adaptive speciation: the role of natural selection in mechanisms of geographic and non-geographic speciation
}

\author{
Jason M. Baker \\ Department of History and Philosophy of Science, Indiana University, Goodbody Hall 130, \\ 1011 East Third Street, Bloomington, IN 47405, USA
}

\begin{abstract}
Recent discussion of mechanism has suggested new approaches to several issues in the philosophy of science, including theory structure, causal explanation, and reductionism. Here, I apply what I take to be the fruits of the 'new mechanical philosophy' to an analysis of a contemporary debate in evolutionary biology about the role of natural selection in speciation. Traditional accounts of that debate focus on the geographic context of genetic divergencenamely, whether divergence in the absence of geographic isolation is possible (or significant). Those accounts are at best incomplete, I argue, because they ignore the mechanisms producing divergence and miss what is at stake in the biological debate. I argue that the biological debate instead concerns the scope of particular speciation mechanisms which assign different roles to natural selection at various stages of divergence. The upshot is a new interpretation of the crux of that debate - namely, whether divergence with gene flow is possible (or significant) and whether the isolating mechanisms producing it are adaptive.
\end{abstract}

(C) 2005 Elsevier Ltd. All rights reserved.

Keywords: Speciation mechanisms; Isolating mechanisms; Reproductive isolation; Natural selection; Adaptation; Spandrels

E-mail address: bakerjm@indiana.edu (J.M. Baker).

1369-8486/\$ - see front matter (C) 2005 Elsevier Ltd. All rights reserved.

doi:10.1016/j.shpsc.2005.03.005 


\section{The paradox of 'adaptive speciation'}

The existence of speciation - the creation of two species from one-is a puzzle for adaptationists. Charles Darwin's theory of evolution by natural selection accounts for the presence of adaptations in a species. Adaptations help organisms perform tasks, such as finding food or evading predators, which allow them to better exploit environmental resources. When resources are limited, adaptations tend to increase organismic fecundity and, consequently, become widespread in the species. ${ }^{1}$ Moreover, as environmental conditions change, so do selective pressures. As a result, a species may acquire rather different traits over time, and biologists may then divide a continuous population-level lineage into different taxonomic species. Linear adaptive evolution may thus involve 'phyletic speciation' in which an ancestral species gives rise to a single descendent species. But phyletic speciation is a straightforward product of natural selection, given sufficient environmental change and certain (namely, non-cladistic) taxonomic practices.

Branching evolution, or speciation proper, occurs when a single species instead splits into two or more contemporaneous descendent species. Branching evolution is less readily explained by natural selection. The problem is that, prima facie, speciation seems to be maladaptive. The traditional definition of speciation derives from Ernst Mayr's biological species concept (BSC), according to which a species is a group of interbreeding populations reproductively isolated from others. ${ }^{2}$ Speciation thus requires the acquisition of traits (called 'isolating mechanisms') that prevent gene flow between diverging populations. Isolating mechanisms eliminate the possibility of fruitful sex between otherwise happy mates. In so doing, they would seem to lower organismic fitness. How, then, could such traits ever evolve? The BSC appears to render impossible any kind of 'adaptive speciation', that is, speciation driven by natural selection. ${ }^{3}$

The paradox of adaptive speciation is this: isolating mechanisms should only benefit organisms when they arise between genetically distinct populations, and yet populations cannot diverge from each other in the face of gene flow between them. 'Adaptive speciation' thus seems to be a contradiction in terms. Darwin himself fully recognized the puzzle. Despite the title of his most famous work, On the origin of species by means of natural selection (1859), he would later write, 'The acquirement by distinct species of mutual sterility ... could not have been effected through natural selection'. ${ }^{4}$ Other biologists were not so pessimistic. Alfred Russel Wallace, for

\footnotetext{
${ }^{1}$ Adaptations are here defined in terms of their origin and current utility; adaptations must have become prevalent in the population because they were selected for their current function. Spandrels (that is, byproducts of natural selection) that happen to be beneficial cannot therefore be adaptations. For discussion, see Gould \& Lewontin (1979); Gould \& Vrba (1982). Cf. Reeve \& Sherman (1993).

${ }^{2}$ Mayr (1963). Something like the biological species concept may have been accepted by Darwin, as well (Kottler, 1978; but see Beatty, 1985).

${ }^{3}$ In keeping with standard usage, I shall use 'adaptive speciation' to designate speciation 'driven' by natural selection, whether directly or indirectly. The contrast here is with 'founder effect' speciation, in which reproductive isolation is achieved by drift.

${ }^{4}$ Darwin (1868), Vol. 2, p. 170.
} 
example, claimed that while hybrid sterility might not benefit organisms it did benefit the species (or, as he called it, the 'form') and, thus, that natural selection explained speciation after all. ${ }^{5}$ Others have argued that group or species selection accounted for the proliferation of new species. While suggestive, such accounts have encountered many serious difficulties. Most contemporary biologists who defend some version of adaptive speciation claim it is driven by organismic selection. ${ }^{6}$ Among those biologists, two approaches to the paradox can be identified.

The first approach, what I call the 'spandrel approach', achieved widespread approbation following the publication of Mayr's Systematics and the origin of species (1942). 'Spandrels' are traits that arise as incidental by-products of natural selection. ${ }^{7}$ According to the spandrel approach, natural selection plays only an indirect role in the evolution of isolating mechanisms. Isolating mechanisms are not themselves selected. Nevertheless, natural selection explains speciation, because adaptive evolution produces reproductive isolation as a by-product. For example, when conspecific populations become geographically isolated (a so-called 'vicariant' event), the populations begin to evolve independently. They may then acquire unique suites of genes in response to their differing environmental conditions. Once the populations are reintroduced, 'chance' incompatibilities that evolved during geographic isolation (for reasons other than reproductive isolation) now prevent gene flow between the new species. Isolating mechanisms are thus spandrels. The spandrel approach solves the problem of speciation by removing the cost of reproductive isolation. Diverging populations could not exchange genes anyway (because of geographic distance), so reproductive incompatibilities can develop with impunity to organismic fitness.

The second approach, what I call the 'adaptive approach', holds that isolating mechanisms are directly selected. Given certain population and ecological structures, reducing gene flow can benefit organisms. Theodosius Dobzhansky, for example, proposed a speciation mechanism (later called 'reinforcement') in which geographically isolated populations come into 'secondary contact' before isolating mechanisms evolve but after the populations have diverged genetically. During secondary contact, natural selection may favour the evolution of isolating mechanisms, which would prevent the dilution of localised adaptation. Those isolating mechanisms would be adaptations for reproductive isolation. They benefit organisms, because they prevent gene flow between genetically distinct populations. Isolating mechanisms thus act as a kind of immune system, preserving the adaptive complexes in each population.

The difference between the two approaches could hardly be starker, at least within an adaptationist framework. ${ }^{8}$ Advocates of the adaptive approach claim that

\footnotetext{
${ }^{5}$ Wallace (1886, 1888); also see Kottler (1985).

${ }^{6}$ This is not to suggest that higher-level selection plays no role in speciation, simply that the participants in contemporary debates about adaptive speciation have generally ignored its potential contributions.

${ }^{7}$ Gould \& Lewontin (1979).

${ }^{8} \mathrm{I}$ adopt an adaptationist framework here, precisely because the puzzle of speciation is how natural selection could produce it.
} 
isolating mechanisms are adaptations; advocates of the spandrel approach claim that isolating mechanisms are adaptational by-products. ${ }^{9}$ Nevertheless, in keeping with standard usage, I call both approaches accounts of 'adaptive speciation', because natural selection drives the evolution of reproductive isolation in both cases. ${ }^{10}$

Controversies about adaptive speciation are traditionally discussed in the context of geography. ${ }^{11}$ Advocates of the spandrel approach argue that geographic speciation is the most common mode of speciation. ${ }^{12}$ Advocates of the adaptive approach defend the theoretical possibility ${ }^{13}$ (and, some, the prevalence in nature ${ }^{14}$ ) of nongeographic speciation. Consequently, the debate has been construed as a controversy about the geography of speciation, about whether isolating mechanisms can or often arise in the absence of geographic isolation. That construal misses what is at stake in the present debate, however. Adaptive isolating mechanisms can arise in the presence or absence of geographic isolation. A new analysis of the controversy is needed.

Recently supporters of the adaptive approach have called for a new taxonomy of speciation, one based on isolating mechanisms. ${ }^{15}$ The suggestion is salutary, in my view, but nevertheless only a start. We must do more than simply focus on the component mechanisms of speciation. We must also examine how those modules interact with each other and with environmental factors in the production of genetic divergence. Present debates ultimately hinge, not on biogeography or even particular isolating mechanisms, but on entire speciation mechanisms - mechanisms which assign different causal roles to natural selection at various stages of divergence.

In this paper, I discuss several speciation mechanisms. The 'new mechanical philosophy' provides tools for analysing those mechanisms and debates about their relative significance. Specifically, the decomposition of speciation mechanisms reveals which steps in the speciation process might be adaptive and for what task. Geographic taxonomies of speciation, in contrast, simply fail to pick out relevant

\footnotetext{
${ }^{9}$ The distinction I wish to draw here is not the familiar selection for-selection of distinction (for which see Sober, 1993). It is not the case that biologists on both sides agree that isolating mechanisms are selected and disagree only about what the isolating mechanisms are selected for (with advocates of the adaptive approach claiming that the isolating mechanisms are selected for reproductive isolation and advocates of the spandrel approach claiming that they are selected for some other function, incidental to reproductive isolation). Certainly, advocates of the adaptive approach contend that isolating mechanisms are selected, and selected for reproductive isolation. Advocates of the spandrel approach, however, do not consider isolating mechanisms to be even potential targets of selection. The incompatible characters are individually selected, on this view, and for functions independent of reproductive isolation. But the incompatibilities per se (that is, the isolating mechanisms themselves) are not selected at all-not for reproductive isolation, not for any other function.

${ }^{10}$ Dieckmann, Doebeli, Metz, \& Tautz (2004), pp. 1-16.

${ }^{11}$ See, for example, the textbook accounts in Brown \& Lomolino (1998); Futuyma (1998); Sterelny \& Griffiths (1999); Schilthuizen (2001); Coyne \& Orr (2004). Cf. Mayr (1942, 1963).

${ }^{12}$ See, for example, Mayr (1942, 1963); Futuyma \& Mayer (1980); Felsenstein (1981); Futuyma (1987, 1988); Barraclough \& Vogler (2000). Cf. Turelli, Barton, \& Coyne (2001); Coyne \& Orr (2004).

${ }^{13}$ See, for example, Maynard Smith (1966); Kondrashov (1986); Dieckmann \& Doebeli (1999); Gavrilets \& Waxman (2002); Fry (2003).

${ }^{14}$ See, for example, Noor (1995); Schluter (2000, 2001); Boughman (2001); Via (2002). See also Rice \& Hostert (1993); Rieseberg (1997).

${ }^{15}$ Via (2001); Kirkpatrick \& Ravigné (2002).
} 
differences among various mechanisms of adaptive speciation. As I shall argue, the new taxonomy I recommend-based on speciation mechanisms - sheds new light on contemporary debates about adaptive speciation.

\section{Mechanisms in biology}

Mechanisms, particularly mechanisms in biology, have recently attracted significant attention. ${ }^{16}$ Several philosophical analyses have been proposed. I adopt here the definition of Machamer, Darden, and Craver: mechanisms are 'entities and activities organised such that they are productive of regular changes from start or setup to finish or termination conditions'. ${ }^{17}$ Some observations are in order.

The phenomenon to be explained (in this case, organic discontinuity) delimits the mechanisms to be described. Clearly, mechanism descriptions cannot explain a domain of phenomena unless the mechanisms produce phenomena in that domain. When comparing mechanisms, we must be clear about the phenomena each produces and the relative explanatory power each holds for the given domain. For example, some advocates of the adaptive approach have argued that non-geographic speciation is simply possible, while others have claimed it is common. We need to be clear about whether competing mechanistic accounts clash over the scope claimed for a particular mechanism or its productive capability.

Mechanisms involve a series of steps that go from start to finish whenever the preconditions obtain. For that to happen there must be a 'productive continuity' between each step. There can be no gaps. For a mechanistic account of speciation to carry full explanatory weight, it must specify the working entities and activities and describe how each step produces the next from parent species to daughter species. $^{18}$

Mechanisms tend to be nested hierarchically. For example, biologists talk about mechanisms of evolution generally, mechanisms producing genetic variation in a population, isolating mechanisms, and mechanisms of speciation. Present controversies about adaptive speciation take mechanisms of variation for granted, for example. ${ }^{19}$ At issue are isolating mechanisms and their role in mechanisms of geographic and non-geographic speciation.

Finally, mechanisms can be represented by 'schemata': abstract descriptions of a mechanism into which specific entities and activities can be instantiated. Complete

\footnotetext{
16 See, for example, Wimsatt (1976); Brandon (1985, 1996); Woodward (1989, 2002); Glennan (1996, 2002); Salmon (1998); Thagard (1998); Machamer, Darden, \& Craver (2000); Craver (2001); Tabery (2004); this issue.

${ }_{17}^{17}$ Machamer, Darden, \& Craver (2000), p. 3.

${ }^{18}$ Biologists seem to acknowledge this in their search for 'laws' of speciation. For example: 'Speciation is ... a law of nature, rather than an accident' (Dieckmann, Doebeli, Metz, \& Tautz, 2004, p. 394); and speciation is 'no accident' (Butlin \& Tregenza, 1997, p. 551).

${ }^{19}$ That was not always the case. Early advocates of non-geographic speciation, among them Galton (1894), Bateson (1894), and de Vries (1901-1903), debated various mechanisms of variation. See also Goldschmidt (1940); Lewis (1978); Gould \& Lewontin (1979); Gould (2002).
} 
schemata are not always available to scientists, however. Mechanisms can also be adumbrated as 'sketches'. Sketches may include black boxes or gaps in the sequence, or perhaps the bottom-out entities and activities are unspecified. Biologists may use the term 'model' to refer to schemata, sketches, or their instances (as in 'model systems' to refer to exemplar cases). Here, I restrict its meaning to hypothesised schemata. Models provide biologists with a wide hypothesis space of possible mechanism schemata for a given case. Empirical evidence can circumscribe within that space a subgroup of plausible mechanism schemata until a single, mostprobable schema remains. Debates about whether some particular schema is instantiated in a particular case cannot adjudicate the question of relative significance in the larger domain, however. Biologists want to know what portion of the domain can be accounted for by this or that mechanism. ${ }^{20}$ Scope delimitation is critical to that aim. ${ }^{21}$

With this general framework in mind we now return to speciation. I first articulate a mechanism of geographic speciation described by Ernst Mayr. I then describe three mechanisms, one geographic and two non-geographic, advocated by proponents of the adaptive approach. The 'new mechanical philosophy' provides several important tools for analysing those mechanisms. In particular, mechanism decomposition, mechanism nesting, and black boxes play important roles in debates about adaptive speciation. By keying into the mechanisms of speciation, rather than geographic context, we can make those roles explicit.

\section{Mayr's mechanism of vicariant speciation}

We begin with a description of a mechanism of geographic speciation, called 'vicariant speciation', taken roughly from Ernst Mayr (see Fig. 1). ${ }^{22}$ The mechanism starts with a single interbreeding population (step 1). Several properties of the population are critical. First, the population is composed of sexually reproducing organisms, and the organisms mate randomly with respect to genotype. Second, there is no immigration into or emigration out of the population. Finally, each member of the population is more closely related to every other member than to any non-member of the population. That is, the population is 'exclusive'. ${ }^{23}$

The mechanism ends with two distinct, non-interbreeding populations (step 5). Each population has all the critical properties of a single interbreeding population; the conjoined 'metapopulation' does not. The populations have overlapping ranges but remain reproductively isolated nevertheless. Moreover, each population is

\footnotetext{
20 Beatty (1995, 1997); Fehr (2001).

21 See Skipper (2002).

22 Mayr (1942), p. 160. The mechanism I describe here is idealised: it has been simplified to such an extent that, when taken literally, it is undoubtedly 'false' (that is, uninstantiated in the real world). Nevertheless, my account mirrors those presented in textbooks and represents, I hope clearly and simply, the core components of the model.

23 Baum \& Shaw (1995).
} 


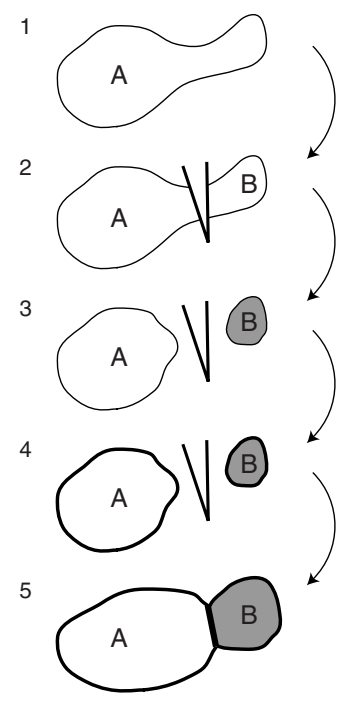

Fig. 1. Vicariant speciation (see Mayr, 1942). A geographic barrier (indicated by the $v$-shaped wedge) divides a single population into two sub-populations, $A$ and $B$, preventing gene flow between them. The sub-populations subsequently diverge genetically (indicated by differential shading) and, as an incidental by-product of that divergence, become reproductively isolated (indicated by dark lines around $A$ and $B$ ). Note that genetic divergence (step 3) and reproductive isolation (step 4) arise in geographic isolation.

'reciprocally monophyletic': the genic lineages within each population coalesce at a common ancestor not shared with the other. ${ }^{24}$

The first stage in speciation is a 'vicariant' event. Some part of the original population is cut off from the rest by a potentially ephemeral barrier, such that the two sub-populations do not exchange genes. In time, the daughter population may experience different selective regimes from those experienced by the parental population. That may result from different environmental conditions or perhaps from differences in sexual selection. In any case, those regimes will likely shape the daughter population such that its component genotypes differ markedly from those of the parental population. ${ }^{25}$

We must be careful at this point to distinguish the third stage from the final two. By step 3, the daughter and parental populations may look very different. They certainly will comprise dissimilar arrays of genetic diversity. However, they are yet races

\footnotetext{
${ }^{24}$ Hudson (1990); Harrison (1998); Avise (2000). That reciprocal monophyly (or 'exclusivity') eventually evolves between newly formed species is uncontested. However, the timing of that event and its taxonomic implications remain highly controversial. For discussion, see Palumbi, Cipriano, \& Hare (2001); Hudson \& Coyne (2002); Baker et al. (2003); Hudson \& Turelli (2003); Funk \& Omland (2004).

${ }^{25}$ Genetic divergence between geographically isolated populations can also be achieved by drift, that is, by chance. Here, I describe only mechanisms of adaptive speciation, since the puzzle of speciation is how natural selection could produce it. For discussion, see Barton \& Charlesworth (1984); Rice \& Hostert (1993); Templeton (1996).
} 
on traditional accounts. At least until step 4, when isolating mechanisms are acquired, the two populations remain conspecific. Should a member of the daughter population be transplanted into the original population during step 3, its genotype would be quickly absorbed. The only constraints keeping the two populations distinct are extrinsic barriers to gene flow, which could always break down. Step 4 is therefore the critical stage of speciation. It is also the most puzzling. Fifty years after Mayr (1942), the process was no less mysterious:

Surprisingly, there is almost no empirical evidence for the most crucial aspect of [vicariant] speciation, the origin of reproductive isolation as a by-product of drift or selection. ... There are two laboratory experiments showing reproductive isolation as a by-product of adaptation, but only one example from nature. $^{26}$

During step 4, intrinsic reproductive isolation is somehow acquired. It establishes permanent barriers to gene flow. Eventually, even artificial transplantation is unable to mix the two gene pools. The question that remains is how this occurs, how do isolating mechanisms evolve during independent adaptive evolution? Do the genes involved in isolating mechanisms frequently have pleiotropic effects, which might be directly selected? Do they frequently tag along in the selection of other genes?

In the final step, the populations are reintroduced yet maintain their unique evolutionary identities (step 5). The populations have diverged in character so much that hybridisation between them is disadvantaged. Selection favours any trait that makes interbreeding less probable (for example, by breeding asynchrony or divergent sexual selection), even after reproductive isolation has been achieved. Although by step 5 isolating mechanisms may directly benefit organisms and although they may be actively maintained by natural selection, isolating mechanisms could not have arisen in either population to prevent intercrossing. That is because, prior to their reintroduction, the populations could not have exchanged genes anyway because of the geographic barrier. Consequently, the prevention of gene flow could not have conferred any benefit. It could only be by happenstance that traits selected during geographic isolation would prevent gene flow after the populations are reintroduced. Isolating mechanisms are spandrels, not adaptations. Speciation is now complete.

The mechanism description above is a sketch, not a schema. Recall that sketches are incomplete mechanism schemata, with black boxes or unspecified bottom-out entities and activities. The origin of intrinsic isolating mechanisms in step 4 remains a black box. Second, the bottom-out activities and entities are unspecified. What are the units of speciation? What entities benefit? What activities are basic? Those questions remain the subjects of active research.

We now consider several mechanisms of adaptive speciation in which reproductive isolation is directly selected.

$\overline{{ }^{26} \text { Coyne }}$ (1992), p. 512. 


\section{Darwin's 'principle of divergence' and non-geographic speciation}

In his earliest writings, Charles Darwin adopted a position not unlike Ernst Mayr's much later one: reproductive isolation usually arose by chance during geographic isolation. In the 'Sketch of 1842' and 'Essay of 1844', for example, Darwin treated reproductive isolation as generally non-adaptive. He claimed that speciation usually occurred in geographic isolation, where a physical barrier prevented intercrossing between newly emerging varieties. Hybrid sterility could evolve with no cost to the organism.

Isolation either by chance landing of a form on an island, or subsidence dividing a continent, or great chain of mountains ... will best favour variation and selection. ... [A geographic] barrier would further act in preventing species formed in one part [from] migrating to another part. ${ }^{27}$

In the Essay, Darwin argued that the effectiveness of breeders in creating new forms depended on their ability to isolate new variants from the rest as soon as they arose in the stocks. Over time, the new variety would be unable to breed successfully with other members of the species. He wrote, 'The circumstances most favourable for variation under domestication ... [include] isolation as perfect as possible of such selected varieties; that is, preventing their crossing with other forms'. ${ }^{28}$

Speciation in nature likewise resulted when varieties became geographically isolated from their kin. Over time, the varieties would become reproductively incompatible. Isolated varieties could not compete for resources, however, so there would be no advantage to their divergence. Any divergence between the new varieties, once isolated, would be entirely by happenstance. Darwin 'had no [direct] link between adaptation and speciation'. ${ }^{29}$

Darwin's 'principle of divergence', developed between 1844 and 1859, would provide that link. ${ }^{30}$ The principle attributed to organisms a tendency to differentiate within a species by a division of labour. Accordingly, 'the more diversified the descendents of any one species become in structure, constitution, and habits, by so much will they be better enabled to seize on many and widely diversified places in the polity of nature, and so be able to increase in numbers'. ${ }^{31}$ Darwin conceived of a selective pressure on organisms to exploit new environmental resources as a means of reducing direct competition. Organisms that acquired the ability to digest novel foods, say, would not need to compete with others over access to food sources. The process of reducing competition in this way led to a diversification of character within a species and, eventually, to the formation of new varieties and their own subsequent divergence. The result was a hierarchical, branching relationship among

27 Darwin (1958a), p. 68.

28 Darwin (1958b), p. 195.

29 Schweber (1980), p. 212.

30 See Sulloway (1979); Ospovat (1981).

31 Darwin (1859), p. 112. 
species. Selection acting to limit competition at all levels could thus explain the biological hierarchy. ${ }^{32}$

Darwin's principle also suggested a mechanism of adaptive speciation. Divergence between varieties (once formed) would directly benefit organisms, according to Darwin's principle, so long as varieties were in direct competition for shared resources. Reproductive isolation would also be adaptive, as varieties increasingly diverged within a species and as hybridisation between varieties became disadvantageous. The characters leading to hybrid sterility would be adaptations for speciation. Geographic isolation was no longer necessary.

I conclude that, although small isolated areas probably have been in some respects highly favourable for the production of new species, yet that the course of modification will generally have been more rapid on large areas; and what is more important, that the new forms produced on large areas, which already have been victorious over many competitors, will be those that will spread most widely, will give rise to the most new varieties and species, and will thus play an important part in the changing history of the organic world. ${ }^{33}$

Darwin's theory of blending inheritance, however, complicated his account of nongeographic speciation. According to Darwin, natural selection acted primarily on 'individual differences', that is, small variations among organisms in a population. ${ }^{34}$ Individual differences were not preserved intact across generations, however. Darwin believed that offspring were usually a blend of their parents' traits (a few traits were 'prepotent' - what Gregor Mendel called 'dominant'). Fleeming Jenkin noted that this view of inheritance was incompatible with Darwin's principle of divergence. Jenkin argued that, because of blending inheritance, most new varieties would be quickly diluted into oblivion, unless intercrossing was prevented or variation was abundant. ${ }^{35}$

Darwin saw the need to respond to these and earlier criticisms. In the fourth edition of the Origin (1866) he wrote, 'It would clearly be advantageous to two varieties or incipient species, if they could be kept from blending, ${ }^{36}$ Likewise, in The variation of animals and plants under domestication (1868), Darwin wrote:

On the principle which makes it necessary for man, whilst he is selecting and improving his domestic varieties, to keep them separate, it would clearly be advantageous to varieties in a state of nature, that is to incipient species, if they could be kept from blending, either through sexual aversion, or by becoming mutually sterile. .. . But when we endeavour to apply the principle of natural selection to the acquirement by distinct species of mutual sterility, we meet with great difficulties. ...

\footnotetext{
32 See Browne (1980).

33 Darwin (1859), p. 106.

34 See Winther (2000).

35 Jenkin (1867).

${ }^{36}$ Darwin (1866), p. 246.
} 
After mature reflection it seems to me that this could not have been effected through natural selection. ${ }^{37}$

Darwin recognised that the prevention of intercrossing between a new variety and the parent species was necessary for speciation, but he could not account for the acquisition of reproductive isolation by natural selection. Recall that, according to Darwin, reproductive isolation could only be adaptive if divergence was already achieved. But how can varieties even form - much less diverge from each other-if novel characters always got swamped out by ancestral characters? Having previously rejected as well the necessity of geographic isolation for producing hybrid sterility, Darwin was unable to adequately answer Jenkin's criticisms.

\section{Post-Darwinian mechanisms of non-geographic speciation}

After the rediscovery of Mendel in the 1900s, Darwin's blending problem dissolved. ${ }^{38}$ Nevertheless, the problem of adaptive speciation persisted. In 1937, Theodosius Dobzhansky's Genetics and the origin of species proposed a new mechanism of adaptive speciation, which, Dobzhansky claimed, was compatible with the newest findings of genetics. Dobzhansky was the major twentieth-century figure who refocused attention on speciation after the views of Hugo de Vries and William Bateson were dismissed in the 1920s and 1930s. Dobzhansky's discussions of speciation are therefore especially relevant to the adaptive speciation controversy.

Dobzhansky shifted attention from the concerns of classical and population geneticists about adaptive variance within populations to the problem of genetic discontinuity between populations - and especially the relationship between genetic and geographic discontinuity. ${ }^{39}$ Importantly, Dobzhansky introduced the study of evolutionary dynamics above the organismic and populational levels. According to Dobzhansky, evolutionary mechanisms occurred at three levels: the gene, the local population, and the species. Evolution required, first, the introduction of genetic variation into a population. Second, activities at the population level (such as selection, migration, and genetic drift) shaped the genetic composition of the population over time. Third, evolutionary change, to be stable, must involve the fixation of variation into discrete arrays of diversity by 'isolating mechanisms' that prevent interbreeding between different species. Speciation was central to Dobzhansky's overall conception of evolution.

By the 1930s, classical and population geneticists had uncovered the basic mechanisms operative at the first two levels. Mutations and gross chromosomal alterations were known to introduce genetic variation, supplying the raw materials of evolution. 'It is now clear', Dobzhansky wrote, 'that gene mutations and

\footnotetext{
37 Darwin (1868), Vol. 2, pp. 169-170.

38 See Darden (1991).

39 See Kohler (1994).
} 
structural and numerical chromosomal changes are the principal sources of variation'. ${ }^{40}$ The action of population-level activities was likewise well understood, at least in principle. But speciation was largely ignored by population geneticists. Dobzhansky claimed that the activities that occupied population geneticists were simply inadequate to explain speciation. Instead, he proposed higher-level mechanisms (namely, isolating mechanisms) to account for the proliferation of new species. Dobzhansky argued that the process of adaptive evolution within populations was governed by mechanisms operative at the gene and population levels (mechanisms of diversification); speciation uniquely involved isolating mechanisms (mechanisms for producing discontinuity). ${ }^{41}$ Without isolation of some kind, Dobzhansky argued, populations could not adapt to local environmental conditions, nor could speciation, adaptive or not, occur.

Dobzhansky described two types of reproductive isolation, geographic and physiological, but only physiological isolating mechanisms necessarily resulted in speciation. He further subdivided physiological isolating mechanisms as follows: ${ }^{42}$

(1) Prezygotic mechanisms
(A) Ecological isolation
(B) Seasonal or temporal isolation
(C) Sexual or psychological isolation
(D) Mechanical isolation
(E) Germ cell incompatibility
(F) Inviability of hybrids

(2) Postzygotic mechanisms
(A) Hybrid sterility

Dobzhansky did not explain how physiological isolating mechanisms arose in a population. 'The mode of origin of these mechanisms remains a puzzle'. ${ }^{43}$ Nevertheless, he held that they developed gradually and usually between geographically isolated populations. Such populations gradually acquired different adaptive complexes according to their own local conditions. Often those complexes were incompatible, and the differences between the populations thereby became fixed. Reproductive isolation was usually an incidental by-product of geographic isolation.

Like Darwin, however, Dobzhansky allowed for the possibility of adaptive isolating mechanisms. ${ }^{44}$ In a process later called 'reinforcement', adaptive isolating mechanisms arose between incompletely diverged populations. Incipient species that diverged in geographic isolation, or by some kind of ecological differentiation (as

\footnotetext{
40 Dobzhansky (1937), p. 118.

41 For further discussion, see Dobzhansky (1935); Krementsov (1994).

42 Dobzhansky (1937), pp. 231-232.

43 Ibid., p. 255.

44 See Beatty (1987) on Dobzhanksy's shift to 'panselectionism' over his career.
} 


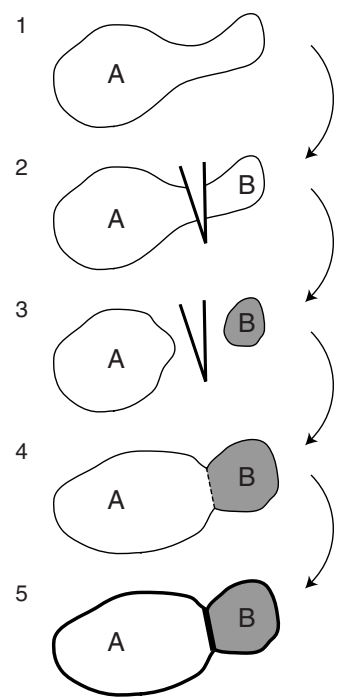

Fig. 2. Speciation by reinforcement (see Dobzhansky, 1937). A geographic barrier divides a single population into two sub-populations, $A$ and $B$, preventing gene flow between them. After the subpopulations diverge genetically (step 3) but before reproductive isolation develops (step 5), $A$ and $B$ come into 'secondary contact', during which there is limited gene flow (indicated by the dotted line). Limited gene flow then prompts the development of adaptive isolating mechanisms. Note that genetic divergence (step 3) arises in geographic isolation but that reproductive isolation (step 5) arises despite limited gene flow.

Darwin's 'principle of divergence' dictated), might later come into 'secondary contact' before physiological isolation was complete. Gene flow between the populations could jeopardise the integrity of the adaptive complexes in each. Dobzhansky argued that 'genetic factors which would decrease the frequency [of] or prevent interbreeding would thereby acquire a positive selective value'. ${ }^{45}$ Geographic contiguity of incipient species could thus prompt the evolution of adaptive isolating mechanisms. 'The basic problem which remains to be settled is how frequently and to what extent can the isolating mechanisms be regarded as adaptational by-products arising without the intervention of special selective processes' ${ }^{46}$ Dobzhansky did not claim that isolating mechanisms were always adaptive, but he did show how that was possible. The question was one of relative significance. In that respect, Dobzhansky stood in strong contrast to Mayr, who insisted on the unimportance of non-geographic speciation.

The mechanism of adaptive speciation Dobzhansky introduced shares many features with Mayr's later one (see Figure 2).

The only difference is that, in Dobzhansky's mechanism, the incipient species are reintroduced before reproductive isolation is achieved. In step 4, the populations

\footnotetext{
45 Dobzhansky (1940), p. 316.

46 Ibid., p. 320 (my emphasis).
} 
come into 'secondary contact', prompting divergent selection. Gene flow between the incipient species could compromise the adaptive complexes that had arisen in each population. Isolating mechanisms are therefore adaptive for the organism. In step 5 , reproductive isolation develops, and speciation is complete.

One problem with Dobzhansky's mechanism is that in step 3 the isolated populations spontaneously diverge enough that interbreeding is maladaptive by step 4 but not enough that isolating mechanisms yet arise. The populations cannot fuse into a single interbreeding population during secondary contact, but neither can they be already reproductively isolated. Consequently, gene flow and hybrid fitness must be low but non-zero. The difficulty is that natural selection drives the formation of isolating mechanisms only in proportion to gene flow. If the populations only rarely interbreed, the adaptive complexes in each will not be greatly jeopardised and selection for further reducing gene flow will be weak. Any increase in reproductive isolation during secondary contact will decrease selection for it. Reinforcement appears self-defeating. ${ }^{47}$ One proposed solution involves sexual selection: if initial divergence results in differences in female tastes for male traits, sexual selection can drive speciation even with limited gene flow. ${ }^{48}$ New models of reinforcement demonstrate a wide parameter space over which speciation is likely to complete during secondary contact. $^{49}$ However, the question remains: what is their scope? The relative importance of reinforcement remains controversial.

Until the mid-1980s, the consensus among evolutionary biologists was that speciation was almost always geographic and isolating mechanisms were almost always adaptational by-products. In 1966, John Maynard Smith introduced a mathematical model demonstrating the possibility of non-geographic speciation. ${ }^{50}$ The parameters of the model were stringent, however, and his paper in fact validated Mayr's general dismissal of non-geographic speciation. Guy Bush was the first field biologist to seriously question the received view, so far as I know. ${ }^{51}$ His case studies of apple maggot fly speciation suggested how non-geographic speciation could proceed by host shift. The maggot flies bred on their feeding grounds, and those that preferred apple fruits tended to form a reproductive community separate from flies preferring hawthorn fruits. What made Bush's data so remarkable was that apple and hawthorn trees, and the races that fed on them, were found in the same geographic area. Something other than geographic distance was preventing gene flow.

For two decades, few evolutionary biologists accepted Bush's interpretations of his fly work. ${ }^{52}$ By the late 1980 s, however, non-geographic speciation found limited support. Most evolutionary biologists (including Mayr) eventually conceded

\footnotetext{
47 See Spencer, McArdle, \& Lambert (1986).

48 Liou \& Price (1994).

49 See Noor (1995); Kelly \& Noor (1996); Turelli, Barton, \& Coyne (2001); Kirkpatrick \& Ravingé (2002).

50 Maynard Smith (1966).

51 Bush (1969). See also Bush (1975); White (1978); Bush \& Butlin (2004).

${ }^{52}$ Futuyma \& Mayer (1980); Felsenstein (1981).
} 
that Bush's data showed non-geographic speciation was possible in certain restricted cases. ${ }^{53}$ In general, Bush demonstrated that, when small mutations cause a change in food preferences, reproductive isolation could arise between varieties occupying the same geographic area. ${ }^{54}$ Nevertheless, Bush's case studies were taken as anomalies to the general rule of geographic speciation. Since Bush's early work, several other systems of non-geographic speciation have been suggested. ${ }^{55}$ Whenever environmental conditions create strong selective pressures against gene flow, isolating mechanisms can evolve by natural selection. ${ }^{56}$ Unsurprisingly, controversies over non-geographic speciation centre on the prevalence of such environmental conditions. ${ }^{57}$

Non-geographic speciation differs in important ways from geographic speciation. Most obviously, divergence is achieved between populations despite gene flow. Many mechanisms of non-geographic speciation have been described. I articulate two: clinal and ecological speciation.

Clinal speciation requires a steep environmental gradient across a series of semiisolated populations, such that selective pressures at one end differ significantly from those at the other end (see Fig. 3). Ecological speciation requires that a population comprise multiple niches over a spatially homogeneous range (see Fig. 4). Both mechanisms thus require particular population, environmental, and genetic structures, the origin of which is not part of the mechanism schema. In both cases, selective regimes differ significantly across a geographic range, prompting divergent selection. In order for speciation to proceed, however, selection against hybridisation must overwhelm the effects of gene flow. That can be accomplished when there is already a differential assortment of genes and there is rampant genic interaction. Consider the following verbal mathematical model (taken from Endler, 1977, pp. 142-151).

Suppose that gene $(A)$ has a high selective value $\left(\mathrm{W}_{A}\right)$ at one region, while an alternate gene $\left(A^{\prime}\right)$ has a high selective value $\left(W_{A^{\prime}}\right)$ at another region. Suppose also that selection favours genes (called 'modifiers') that make the combination of $A$ and $A^{\prime}$ deleterious to the organism. Excessive leakage of gene $A$ from its region into the other region dilutes the benefits gene $A^{\prime}$ confers in its own region. Divergent selection will then result whenever $\mathrm{W}_{A}+\mathrm{W}_{A^{\prime}}>2 \mathrm{~W}_{A A^{\prime}}$. The controversy over ecological and clinal speciation focuses on the extent to which those conditions obtain. A further issue is how biologists could ever determine whether a particular speciation event is the result of non-geographic divergence or secondary contact. Even if biologists could show that selection is driving the evolution of isolating mechanisms between two contiguous populations, it is hard to determine the geographic conditions of initial divergence.

In general, mechanisms of non-geographic speciation impose stringent requirements on the necessary population and ecological structure. For selection to drive

\footnotetext{
53 Kondrashov (1986); Feder, Chilcote, \& Bush (1988).

54 See Berlocher \& Feder (2002).

55 For review, see Via (2001).

56 Tregenza \& Butlin (1999).

57 See Dieckmann, Doebeli, Metz, \& Tautz (2004).
} 


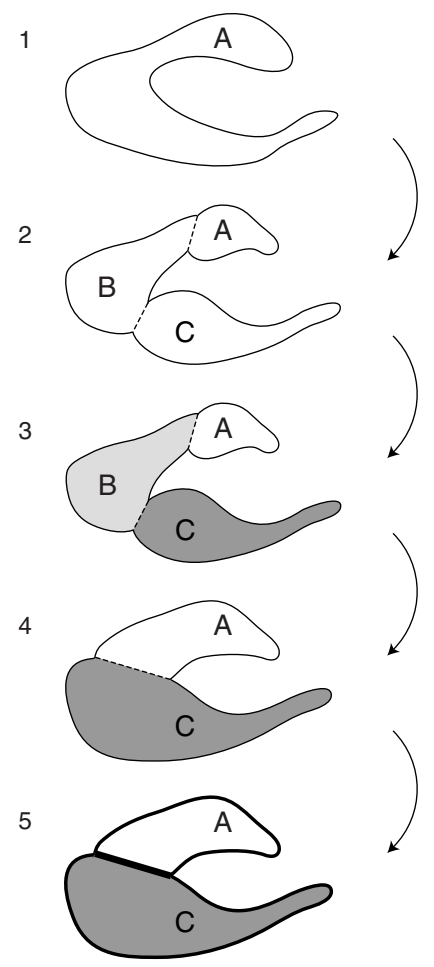

Fig. 3. Clinal speciation (see Endler, 1977). The ancestral population occupies a spatially heterogeneous range, across which environmental factors grade from one extreme to another. The population is segmented into a series of semi-isolated sub-populations, $A, B$, and $C$. Over time, gradual changes in various character traits - 'clines' - e2erge along the environmental gradient, such that individuals at the extremes $(A$ and $C$ ) differ markedly. Intermediate variation is eradicated, and a hybrid zone emerges between $A$ and $C$. Limited gene flow then prompts the development of adaptive isolating mechanisms. Note that genetic divergence (step 3) and reproductive isolation (step 5) arise despite limited gene flow.

speciation, adaptations for environmental tasks must be somehow linked with traits determining mating preferences (as with Bush's flies). Alternatively, character displacement across multiple niches could produce reproductive isolation (as with the mechanisms above). How exactly that happens, in either case, remains a black box.

New models of clinal and ecological speciation have been recently suggested which attempt to overcome some of the more pressing challenges to non-geographic speciation. ${ }^{58}$ Those models explicitly resist the 'idealisations' of geographic mechanisms and instead assume non-random mating and stochastic, multi-locus genetics. One motivation for this shift away from the single-locus models of, for example, Maynard Smith is an effort to increase the verisimilitude of mechanism models. The general argument goes something like this: non-geographic speciation may indeed appear nearly impossible to achieve, given the simplifying assumptions

\footnotetext{
${ }^{58}$ For review, see Johnson et al. (1996); Dieckmann \& Doebeli (2004).
} 


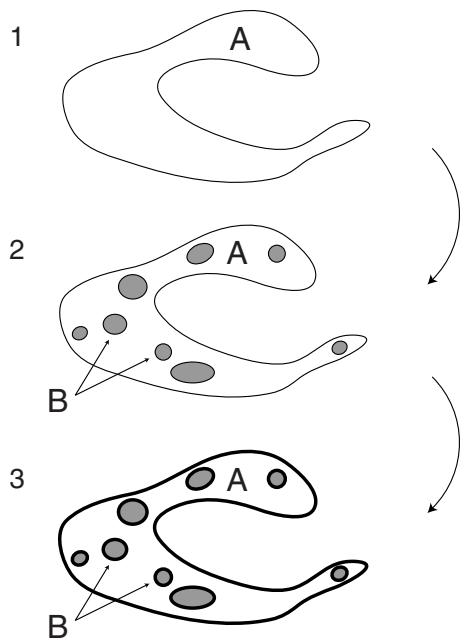

Fig. 4. Ecological speciation (see Bush, 1969). The ancestral population occupies a spatially homogeneous range, and genetic variation has no geographic structure. Ecological divergence nevertheless develops, in which geographically overlapping sub-populations $(A$ and $B)$ exploit different ecological resources (indicated by grey circles). Gene flow between $A$ and $B$ is thereby reduced, and the sub-populations diverge genetically. Limited gene flow then prompts the development of adaptive isolating mechanisms. Note that genetic divergence (step 2) and reproductive isolation (step 3) arise despite limited gene flow.

standardly invoked from population genetics, but more biologically realistic models (models necessarily more complex and synergistic) reveal a wide parameter space in which adaptive isolating mechanisms might evolve. An important contribution of these new models has been the recognition that speciation is likely the result of several (individually insufficient) factors which interact with each other to produce genetic divergence. ${ }^{59}$ Although divergent habitat preferences, low hybrid fitness, modifier genes, and other specific genetic and population structures are each unlikely either to emerge in a population or to produce reproductive isolation, the likelihood that some combination will do so is much higher-particularly with the assumption of stochastic genetics. The challenge for advocates of the adaptive approach continues to be the construction of realistic and robust models of non-geographic speciation which integrate the relevant component mechanisms of genetic, ecological, and sexual divergence.

\section{The spandrel approach and the adaptive approach: a reassessment}

I have briefly described four speciation mechanisms: vicariant, reinforcement, clinal, and ecological. ${ }^{60}$ In each, we can identify three component mechanisms that

\footnotetext{
59 Kawecki (2004).

${ }^{60}$ Darwin's 'principle of divergence' can be thought of as a kind of ecological speciation.
} 
operate at three distinct hierarchical levels. First, mechanisms of genetic variation produce organismic diversity within populations. Second, mechanisms of population divergence produce new varieties. Third, isolating mechanisms produce new species. (See Table 1.)

Table 1

Natural selection and modes of speciation.

\begin{tabular}{lllll}
\hline & SPANDREL APPROACH & ADAPTIVE APPROACH & \\
\cline { 2 - 5 } & Vicariant & Reinforcement & Clinal & Ecological \\
\hline $\begin{array}{c}\text { Mechanisms of } \\
\text { genetic variation } \\
\begin{array}{c}\text { Mechanisms of } \\
\text { population divergence }\end{array}\end{array}$ & Non-adaptive & Non-adaptive & Non-adaptive & Non-adaptive \\
\begin{tabular}{llll} 
Isolating mechanisms \\
\hline
\end{tabular} & Non-adaptive & Non-adaptive & Adaptive & Adaptive \\
\hline
\end{tabular}

Advocates of the two approaches agree that mechanisms of genetic variation are non-adaptive. The specific variants produced by chromosomal inversions or point mutations, for instance, are decoupled from the particular environmental challenges organisms face. Controversies about adaptive speciation are instead controversies about the role of natural selection in the latter two mechanisms. Are mechanisms of population divergence and isolating mechanisms adaptive for organisms? Yes, according to the adaptive approach. ${ }^{61}$ Advocates of the spandrel approach, however, claim that population divergence and isolating mechanisms are spandrels, byproducts of independent adaptive evolution following geographic isolation.

The question of whether speciation is adaptive is a question of the relative significance of the several speciation mechanisms I discussed above (see Fig. 5 for summary). In particular, it is a question of the prevalence of certain population structures. There is no disagreement among biologists about what would happen if given conditions obtain. That is, the dynamics of mathematical models of speciation are uncontested. If populations usually occupy spatially divergent, continuous ranges and if environmental gradients are common, then clinal speciation would be an important mode of speciation. But biologists are not agreed on the extent to which the start-up conditions of the mechanisms are satisfied in nature.

The flow chart in Figure 5 specifies the population structures associated with various speciation mechanisms. Controversies over 'modes of speciation' are, at base, controversies over the usual structure of natural populations-but not just the geographic structure. Note that adaptive speciation can occur between contiguous as well as geographically isolated populations. Ecological and population structure play important roles, as well.

Relative significance debates over speciation mechanisms persist in part because each mechanism can produce the same result: namely, contiguous, reproductivelyisolated species. Unless speciation is very recent, the molecular signatures of a

\footnotetext{
${ }^{61}$ Reinforcement requires only adaptive isolating mechanisms; mechanisms of population divergence are non-adaptive.
} 


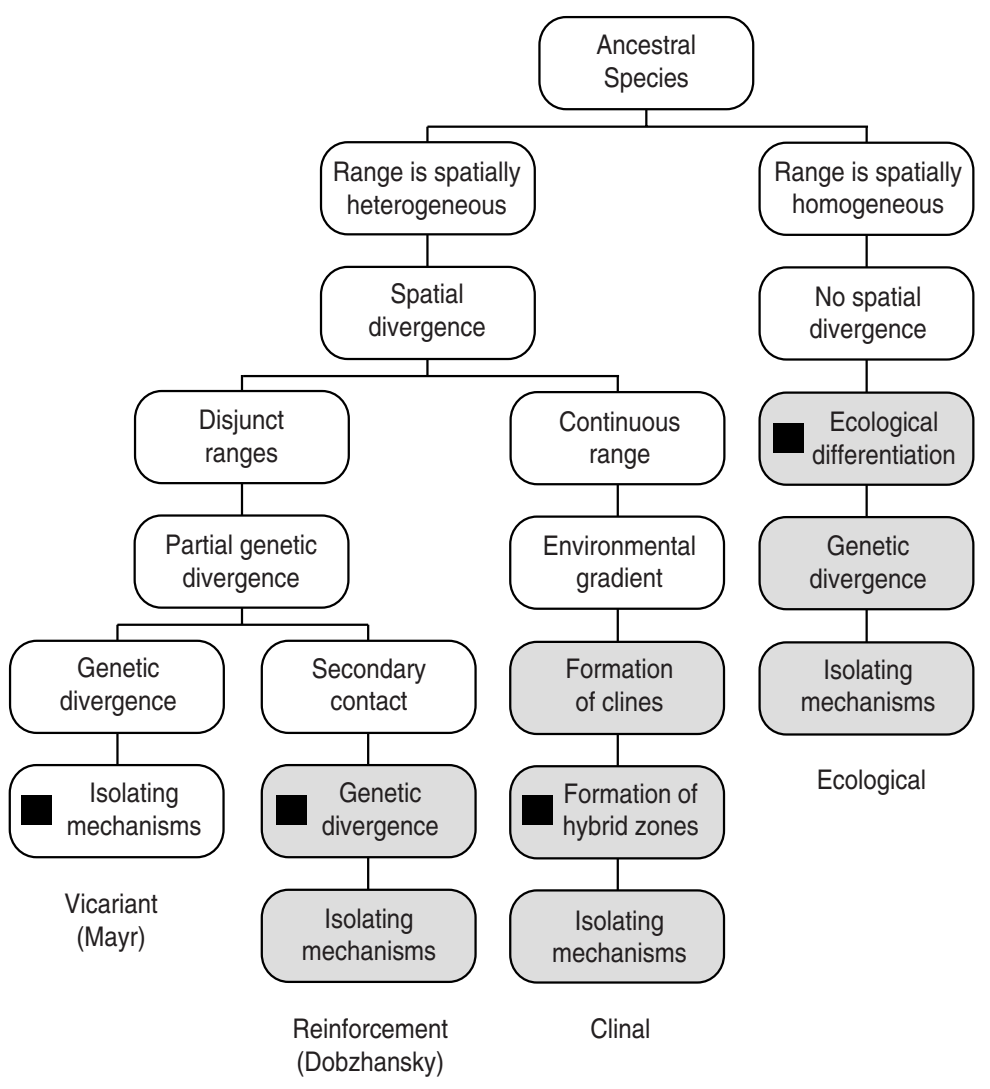

Fig. 5. Comparison of four speciation mechanisms (from Endler, 1977, p. 13, used with permission). Vicariant, reinforcement, clinal, and ecological mechanisms of speciation occur under different geographic, ecological, and population genetic conditions. Potentially adaptive steps are highlighted in grey; steps with significant black boxes are marked with a black square. Note that the potential adaptedness of reproductive isolation is independent of the geographic context of genetic divergence. (Genetic divergence occurs in geographic isolation in both vicariant and reinforcement mechanisms, for example.)

particular speciation mechanism will be erased. ${ }^{62}$ Worse, because the mechanism descriptions above all fail to explain the acquisition of intrinsic isolating mechanisms, cases of incipient speciation will be difficult to classify (note the black squares in Fig. 5). Nevertheless, biologists provide several 'how-possibly' explanations for the emergence of isolating mechanisms, which could potentially be tested. Although incomplete, mechanism sketches provide guidance for discovering actual mechanisms. By identifying gaps in knowledge, black boxes suggest research programmes for testing possible mechanisms. Once complete and after their scope of application is determined, mechanism schemata can provide a resolution to relative significance debates about adaptive speciation.

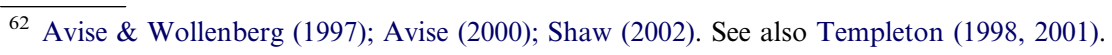


The 'new mechanistic philosophy' provides tools for constructing a new taxonomy of speciation, one which better frames disagreements about the role of natural selection in the evolution of reproductive isolation. Instead of classifying speciation mechanisms according to geography, we ought to pay more attention to gene flow-for which, after all, geography originally stood as a proxy. The basic disagreement between advocates of the two approaches concerns the frequency of speciation in the face of gene flow. Advocates of the adaptive approach claim that isolating mechanisms often arise between freely interbreeding populations. Advocates of the spandrel approach, in contrast, aver that gene flow almost always stymies speciation. Geographic taxonomies obscure this important disagreement, one which, not incidentally, lies at the crux of the paradox of speciation. Speciation necessarily requires the cessation (or drastic reduction) of gene flow, and yet it would seem to be maladaptive for organisms to contribute to such an enterprise. Models of adaptive speciation mechanisms thus aim to demonstrate that natural selection can drive the evolution of isolating mechanisms under realistic biological conditions, despite gene flow. The mechanistic taxonomy I recommend better makes sense of that aim and of current biological research.

Finally, it is now obvious that speciation per se is not adaptive or maladaptive, or at least that the question is irrelevant to interesting biological research. Rather, particular steps in speciation are potentially adaptive, as are particular component mechanisms of genetic, ecological, and sexual divergence. The decomposition of speciation mechanisms is therefore critical to any evaluation of their adaptive import. That decomposition must be coupled with the realisation that the modules cannot ultimately be studied in isolation, however. We must eventually reassemble the pieces and assess their interactions, before we conclude that any one module can or cannot contribute to the evolution of adaptive isolating mechanisms.

\section{Conclusions}

The existence of speciation is a puzzle for Darwin's theory of natural selection. According to the biological species concept, speciation requires the evolution of reproductive isolation between two sub-populations. But how could organisms ever benefit by cutting off sex with potential mates? Biologists have attempted to answer this question in two general ways: the 'adaptive approach', which holds that isolating mechanisms are directly selected, and the 'spandrel approach', according to which isolating mechanisms arise as an incidental by-product of geographic isolation. Several mechanisms of geographic and non-geographic speciation have been discussed. By decomposing those mechanisms, it becomes apparent which steps in the speciation process could be adaptive. In general, organisms will benefit directly from speciation only when population divergence is already present and when, as in secondary contact, competition between diverging populations is maintained. Otherwise, isolating mechanisms will not be selected. Decomposing speciation mechanisms also reveals which steps remain black boxes and suggests where further work might be done. Finally, we locate the source of controversies about the role of natural 
selection in speciation. In short, such controversies are controversies about the prevalence of genetic divergence in the face of gene flow-controversies which ultimately hinge on further controversies about the usual structure of natural populations.

\section{Acknowledgements}

For helpful comments on previous versions of this paper, I thank Carl Craver, Lindley Darden, Melinda Fagan, Sandra Herbert, Lisa Lloyd, Kevin Omland, Jessica Pfeifer, Kerry Shaw, members of the Washington, DC, History and Philosophy of Biology Discussion Group, and three anonymous reviewers for this journal. Remaining errors are of course my own.

\section{References}

Avise, J. C. (2000). Phylogeography: The history and formation of species. Cambridge, MA: Harvard University Press.

Avise, J. C., \& Wollenberg, K. (1997). Phylogenetics and the origin of species. Proceedings of the National Academy of Sciences, USA, 94, 7748-7755.

Baker, J. M., López-Medrano, E., Navarro-Sigüenza, A. G., Rojas-Soto, O. R., \& Omland, K. E. (2003). Recent speciation in the Orchard Oriole group: Divergence of Icterus spurius spurius and Icterus spurius fuertesi. Auk, 120, 848-859.

Barraclough, T. G., \& Vogler, A. P. (2000). Detecting the geographical pattern of speciation from specieslevel phylogenies. American Naturalist, 155, 419-434.

Barton, N. H., \& Charlesworth, B. (1984). Genetic revolutions, founder effects, and speciation. Annual Review of Ecology and Systematics, 15, 133-164.

Bateson, W. (1894). Materials for the study of variation. New York: Macmillan.

Baum, D. A., \& Shaw, K. L. (1995). Genealogical perspectives on the species problem. In P. C. Hoch, \& A. G. Stephenson (Eds.), Experimental and molecular approaches to plant biosystematics (pp. 289-303). St. Louis: Missouri Botanical Garden.

Beatty, J. (1985). Speaking of species: Darwin's strategy. In D. Kohn (Ed.), The Darwinian heritage (pp. 265-281). Princeton, NJ: Princeton University Press.

Beatty, J. (1987). Dobzhansky and drift: Facts, values, and chance in evolutionary biology. In L. Kruger et al. (Eds.), The probabilistic revolution, Vol. 2 (pp. 271-311). Cambridge, MA: MIT Press.

Beatty, J. (1995). The evolutionary contingency thesis. In J. G. Lennox, \& G. Wolters (Eds.), Concepts, theories, and rationality in the biological sciences (pp. 45-81). Pittsburgh: University of Pittsburgh Press.

Beatty, J. (1997). Why do biologists argue like they do? Philosophy of Science, 64(Suppl.), S432-S443.

Berlocher, S. H., \& Feder, J. L. (2002). Sympatric speciation in phytophagous insects: Moving beyond controversy?. Annual Review of Entomology, 47, 773-815.

Boughman, J. W. (2001). Divergent sexual selection enhances reproductive isolation in sticklebacks. Nature, 411, 944-948.

Brandon, R. N. (1985). Grene on mechanism and reductionism: More than just a side issue. In P.D. Asquith \& P. Kitcher (Eds.), PSA 1984, Vol. 2 (pp. 345-353). East Lansing, MI: Philosophy of Science Association.

Brandon, R. N. (1996). Reductionism versus holism versus mechanism. In idem, Concepts and methods in evolutionary biology (pp. 179-204). Cambridge: Cambridge University Press.

Brown, J. H., \& Lomolino, M. V. (1998). Biogeography (2nd ed.). Sunderland, MA: Sinauer.

Browne, J. (1980). Darwin's botanical arithmetic and the 'principle of divergence', 1854-1858. Journal of the History of Biology, 13, 53-89. 
Bush, G. L. (1969). Sympatric host race formation and speciation in frugivorous flies of the genus Rhagoletis (Diptera: Tephritidae). Evolution, 23, 237-251.

Bush, G. L. (1975). Modes of animal speciation. Annual Review of Ecology and Systematics, 6, 339-364.

Bush, G. L. \& Butlin, R.K. (2004). Sympatric speciation in insects. In U. Dieckmann et al. (Eds.), Adaptive speciation (pp. 229-248). Cambridge: Cambridge University Press.

Butlin, R. K., \& Tregenza, T. (1997). Is speciation no accident?. Nature, 387, 551-553.

Coyne, J. A. (1992). Genetics and speciation. Nature, 355, 511-515.

Coyne, J. A., \& Orr, H. A. (2004). Speciation. Sunderland, MA: Sinauer.

Craver, C. F. (2001). Role functions, mechanisms, and hierarchy. Philosophy of Science, 68, 53-74.

Darden, L. (1991). Theory change in science: Strategies from Mendelian genetics. New York: Oxford University Press.

Darwin, C. (1859). On the origin of species by means of natural selection, or the preservation of favoured races in the struggle for life. London: J. Murray.

Darwin, C. (1866). The origin of species by means of natural selection (4th ed.). London: J. Murray.

Darwin, C. (1868). The variation of animals and plants under domestication (2 vols.). London: J. Murray.

Darwin, C. (1958a). Sketch of 1842. In F. Darwin (Ed.), Evolution by natural selection (pp. 37-88). Cambridge: Cambridge University Press. (First published in 1909).

Darwin, C. (1958b). Essay of 1844. In F. Darwin (Ed.), Evolution by natural selection (pp. 89-254). Cambridge: Cambridge University Press. (First published 1909).

de Vries, H. (1901-1903). Die Mutationstheorie: Versuche und Beobachtungen über die Entstehung der Arten im Pflanzenreich (2 vols.). Leipzig: Veit.

Dieckmann, U., \& Doebeli, M. (1999). On the origin of species by sympatric speciation. Nature, 400, 354-357.

Dieckmann, U., \& Doebeli, M. (2004). Adaptive dynamics of speciation: Sexual populations. In U. Dieckmann et al. (Eds.), Adaptive speciation (pp. 76-111). Cambridge: Cambridge University Press.

Dieckmann, U., Doebeli, M., Metz, J. A. J., \& Tautz, D. (Eds.). (2004). Adaptive speciation. Cambridge: Cambridge University Press.

Dobzhansky, T. (1935). A critique of the species concept in biology. Philosophy of Science, 2, 344-355.

Dobzhansky, T. (1937). Genetics and the origin of species. New York: Columbia University Press.

Dobzhansky, T. (1940). Speciation as a stage in evolutionary divergence. American Naturalist, 74, 312-321.

Endler, J. A. (1977). Geographic variation, speciation, and clines. Princeton, NJ: Princeton University Press.

Feder, J. L., Chilcote, C. A., \& Bush, G. L. (1988). Genetic differentiation between sympatric host races of Rhagoletis pomonella. Nature, 336, 61-64.

Fehr, C. (2001). The evolution of sex: Domains and explanatory pluralism. Biology and Philosophy, 16, $145-170$.

Felsenstein, J. (1981). Skepticism towards Santa Rosalia, or why are there so few kinds of animals? Evolution, 35, 124-138.

Fry, J. D. (2003). Multilocus models of sympatric speciation: Bush versus Rice versus Felsenstein. Evolution, 57, 1735-1746.

Funk, D. J., \& Omland, K. E. (2004). Species-level paraphyly and polyphyly: Frequency, causes, and consequences, with insights from animal mitochondrial DNA. Annual Review of Ecology, Evolution, and Systematics, 34, 397-423.

Futuyma, D. J. (1987). On the role of species in anagenesis. American Naturalist, 130, 465-473.

Futuyma, D. J. (1988). Sturm und Drang and the evolutionary synthesis. Evolution, 42, 217-226.

Futuyma, D. J. (1998). Evolutionary biology (3rd ed.). Sunderland, MA: Sinauer.

Futuyma, D. J., \& Mayer, G. C. (1980). Non-allopatric speciation in animals. Systematic Zoology, 29, 254-271.

Galton, F. (1894). Discontinuity in evolution. Mind, 11, 362-372.

Gavrilets, S., \& Waxman, D. (2002). Sympatric speciation by sexual conflict. Proceedings of the National Academy of Sciences, USA, 99, 10533-10538.

Glennan, S. (1996). Mechanisms and the nature of causation. Erkenntnis, 44, 49-71.

Glennan, S. (2002). Rethinking mechanistic explanation. Philosophy of Science, 69(Suppl.), S342-S353. 
Goldschmidt, R. B. (1940). The material basis of evolution. New Haven, CT: Yale University Press.

Gould, S. J. (2002). The structure of evolutionary theory. Cambridge, MA: Harvard University Press.

Gould, S. J., \& Lewontin, R. C. (1979). The spandrels of San Marco and the Panglossian paradigm: A critique of the adaptationist programme. Proceedings of the Royal Society, London, Series B, 205, 581-598.

Gould, S. J., \& Vrba, E. S. (1982). Exaptation: A missing term in the science of form. Paleobiology, 8, $4-15$.

Harrison, R. G. (1998). Linking evolutionary pattern and process: The relevance of species concepts for the study of speciation. In D. J. Howard, \& S. H. Berlocher (Eds.), Endless forms: Species and speciation (pp. 19-31). New York: Oxford University Press.

Hudson, R. R. (1990). Gene genealogies and the coalescent process. In D. J. Futuyma, \& J. Antonovics (Eds.), Oxford surveys in evolutionary biology, Vol. 7 (pp. 1-44). Oxford: Oxford University Press.

Hudson, R. R., \& Coyne, J. A. (2002). Mathematical consequences of the genealogical species concept. Evolution, 56, 1557-1565.

Hudson, R. R., \& Turelli, M. (2003). Stochasticity overrules the 'three-times rule': Genetic drift, genetic draft, and coalescence times for nuclear loci versus mitochondrial DNA. Evolution, 57, $182-190$.

Jenkin, F. (1867). The origin of species. North British Review, 44, 277-318.

Johnson, P. A., Hoppenstaedt, F. C., Smith, J. J., \& Bush, G. L. (1996). Conditions for sympatric speciation: A diploid model incorporating habitat fidelity and non-habitat assortative mating. Evolutionary Ecology Research, 10, 187-205.

Kawecki, T. J. (2004). Genetic theories of sympatric speciation. In Dieckmann et al. (Eds.), Adaptive speciation (pp. 36-53). Cambridge: Cambridge University Press.

Kelly, J. K., \& Noor, M. A. F. (1996). Speciation by reinforcement: A model derived from studies of Drosophila. Genetics, 143, 1485-1497.

Kirkpatrick, M., \& Ravigné, V. (2002). Speciation by natural and sexual selection: Models and experiments. American Naturalist, 159(Suppl.), S22-S35.

Kohler, R. E. (1994). Lords of the fly: Drosophila genetics and the experimental life. Chicago: University of Chicago Press.

Kondrashov, A. S. (1986). Multilocus model of sympatric speciation, III. Computer simulations. Theoretical Population Biology, 29, 1-15.

Kottler, M. J. (1978). Charles Darwin's biological species concept and theory of geographic speciation: The transmutation notebooks. Annals of Science, 35, 275-297.

Kottler, M. J. (1985). Charles Darwin and Alfred Russel Wallace: Two decades of debate over natural selection. In D. Kohn (Ed.), The Darwinian heritage (pp. 367-432). Princeton, NJ: Princeton University Press.

Krementsov, N. L. (1994). Dobzhansky and Russian entomology: The origin of his ideas on species and speciation. In M. B. Adams (Ed.), The evolution of Theodosius Dobzhansky: Essays on his life and thought in Russia and America (pp. 31-48). Princeton, NJ: Princeton University Press.

Lewis, E. B. (1978). A gene complex controlling segmentation in Drosophila. Nature, 276, 565-570.

Liou, L. W., \& Price, T. D. (1994). Speciation by reinforcement of prezygotic isolation. Evolution, 48, 234-243.

Machamer, P., Darden, L., \& Craver, C. F. (2000). Thinking about mechanisms. Philosophy of Science, 67, $1-25$.

Maynard Smith, J. (1966). Sympatric speciation. American Naturalist, 100, 637-650.

Mayr, E. (1942). Systematics and the origin of species: From the viewpoint of a zoologist. New York: Columbia University Press.

Mayr, E. (1963). Animal species and evolution. Cambridge, MA: Harvard University Press.

Noor, M. A. F. (1995). Speciation driven by natural selection in Drosophila. Nature, 375, 674-675.

Ospovat, D. (1981). The development of Darwin's theory: Natural history, natural theology, and natural selection, 1838-1859. Cambridge: Cambridge University Press.

Palumbi, S. R., Cipriano, F., \& Hare, M. P. (2001). Predicting nuclear gene coalescence from mitochondrial data: The three-times rule. Evolution, 55, 859-868. 
Reeve, H. K., \& Sherman, P. W. (1993). Adaptation and the goals of evolutionary research. Quarterly Review of Biology, 68, 1-32.

Rice, W. R., \& Hostert, E. E. (1993). Laboratory experiments on speciation: What have we learned in 40 years?. Evolution, 47, 1637-1653.

Rieseberg, L. H. (1997). Hybrid origins of plant species. Annual Review of Ecology and Systematics, 28, 359-389.

Salmon, W. C. (1998). Causality and explanation. Oxford: Oxford University Press.

Schilthuizen, M. (2001). Frogs, flies, and dandelions: Speciation — the evolution of new species. Oxford: Oxford University Press.

Schluter, D. (2000). The ecology of adaptive radiation. Oxford: Oxford University Press.

Schluter, D. (2001). Ecology and the origin of species. Trends in Ecology and Evolution, 16, 372-380.

Schweber, S. S. (1980). Darwin and the political economists: Divergence of character. Journal of the History of Biology, 13, 195-289.

Shaw, K. L. (2002). Conflict between nuclear and mitochondrial DNA phylogenies of a recent species radiation: What mtDNA reveals and conceals about modes of speciation in Hawaiian crickets. Proceedings of the National Academy of Sciences, USA, 99, 16122-16127.

Skipper, R. A., Jr. (2002). The persistence of the R.A. Fisher-Sewall Wright controversy. Biology and Philosophy, 17, 341-367.

Sober, E. (1993). The nature of selection: Evolutionary theory in philosophical focus. Chicago: University of Chicago Press. (First published 1984)

Spencer, H. G., McArdle, B. H., \& Lambert, D. M. (1986). A theoretical investigation of speciation by reinforcement. American Naturalist, 128, 241-262.

Sterelny, K., \& Griffiths, P. E. (1999). Sex and death: An introduction to philosophy of biology. Chicago: University of Chicago Press.

Sulloway, F. J. (1979). Geographic isolation in Darwin's thinking: The vicissitudes of a crucial idea. Studies in History of Biology, 3, 23-65.

Tabery, J. G. (2004). Synthesizing activities and interactions in the concept of a mechanism. Philosophy of Science, $71,1-15$.

Templeton, A. R. (1996). Experimental evidence for the genetic-transilience model of speciation. Evolution, 50, 909-915.

Templeton, A. R. (1998). Species and speciation: Geography, population structure, ecology, and gene trees. In D. J. Howard, \& S. H. Berlocher (Eds.), Endless forms: Species and speciation (pp. 32-43). New York: Oxford University Press.

Templeton, A. R. (2001). Using phylogeographic analyses of gene trees to test species status and processes. Molecular Ecology, 10, 779-791.

Thagard, P. (1998). Explaining disease: Causes, correlations, and mechanisms. Minds and Machines, 8, 61-78.

Tregenza, T., \& Butlin, R. K. (1999). Speciation without isolation. Nature, 400, 311-312.

Turelli, M., Barton, N., \& Coyne, J. A. (2001). Theory and speciation. Trends in Ecology and Evolution, 16, $330-343$.

Via, S. (2001). Sympatric speciation in animals: The ugly duckling grows up. Trends in Ecology and Evolution, 16, 381-390.

Via, S. (2002). The ecological genetics of speciation. American Naturalist, 159 (Suppl.), S1-S7.

Wallace, A. R. (1886). Romanes versus Darwin. Fortnightly Review, 46, 300-316.

Wallace, A. R. (1888). Darwinism: An exposition of the theory of natural selection with some of its applications. London: Macmillan.

White, M. J. D. (1978). Modes of speciation. San Francisco, CA: W.H. Freeman.

Wimsatt, W. C. (1976). Reductive explanation: A functional account. In A. C. Michalos et al. (Eds.), PSA 1974 (pp. 671-710). Dordrecht: Reidel.

Winther, R. G. (2000). Darwin on variation and heredity. Journal of the History of Biology, 33, 425-455.

Woodward, J. (1989). The causal mechanical model of explanation. In P. Kitcher, \& W. C. Salmon (Eds.), Scientific explanation (pp. 357-383). Minneapolis: University of Minnesota Press.

Woodward, J. (2002). What is a mechanism? A counterfactual account. Philosophy of Science, 69(Suppl.), S366-S377. 